\title{
Monomujer, teatro para un espectador y para Ixs amantes del arte del detalle
}

\section{Evangelina Ramos}

En el Centro Cultural San Martín, durante la temporada de verano, las Monomujer volvieron para convidarnos teatro para un espectador. Luego de cinco años de trabajo ininterrumpido, de escribir, dirigir y actuar sus obras, regresaron con Interior, que es fundamentalmente un viaje, inquietante e inclusivo, que invita a lxs espectadores, mediante la puesta en escena de dos micromónologos, a entregarse a un acontecimiento teatral sorprendente. Quien decide formar parte de esta experiencia tiene que estar dispuesto a ser interpeladx de un modo casi intimidante.

Allá por el 2016, esta compañía de teatro de mujeres, actualmente conformada por ocho integrantes, comenzó a transitar un camino que las condujo por diversos teatros de la escena porteña. Con sus pequeños gabinetes desembarcaron en la sala de espera de Timbre 4 y en el Centro Cultural Sábato, en el Cultural San Martín, entre otros, y hasta formaron parte de la programación del FIBA 2020, siempre abordando en sus obras temas como la migración, la diversidad y la sociedad patriarcal en la que vivimos.

Interior, particularmente, fue creado durante el aislamiento debido a la pandemia Covid-19 durante el 2020. Sus dos propuestas La Perla y María, alas de Caráu tienen textos originales y sensibles anclados en temáticas urgentes. El primero nos sumerge en un universo onírico y realista a la vez: una mujer mirándonos a los ojos de modo permanente nos habla de sus sueños, en lxs que hace referencia a la dictadura, al abuso, con una delicada prosa matizada con elementos poéticos; mientras que María, alas Del Caráu es la historia de una mujer del interior que, dedicada al trabajo de cuidado, es explotada y culpada de una muerte de la que lejos está de ser responsable.

La labor interpretativa llevada adelante por cada una de las actrices le otorga a cada pieza un gran efecto de realidad. Gracias a su trabajo corporal expresivo, cada micromonólogo alcanza una verosimilitud sorprendente, que conduce al espectador a inmiscuirse de modo profundo en la trama de cada propuesta. Una performance adecuada de las voces contribuye a la construcción de la singularidad de lxs personajes representadxs: la cadencia en el habla que logra Jimena García Conde en María del Carau, propia de una persona originaria del interior de nuestro país, es impecable, al igual que los matices que alcanza Virginia Curet en La Perla. Olave Mendoza, a la vez, quién interpreta a la mujer que lleva adelante la tarea de limpieza mientras nos acompaña en el tránsito de un gabinete a otro, ofrece un personaje que se destaca por su delicadeza y precisión en su despliegue escénico. Al reflexionar sobre los espacios 
donde se lleva adelante cada pieza, de igual modo, podemos descubrir una puesta del detalle, cada elemento de la escenografía elegida es adecuado a los fines de invitar al espectador a entregarse a cada universo. Las plantas en María alas del Caráu, la arena en La perla, por nombrar solo algunos elementos.
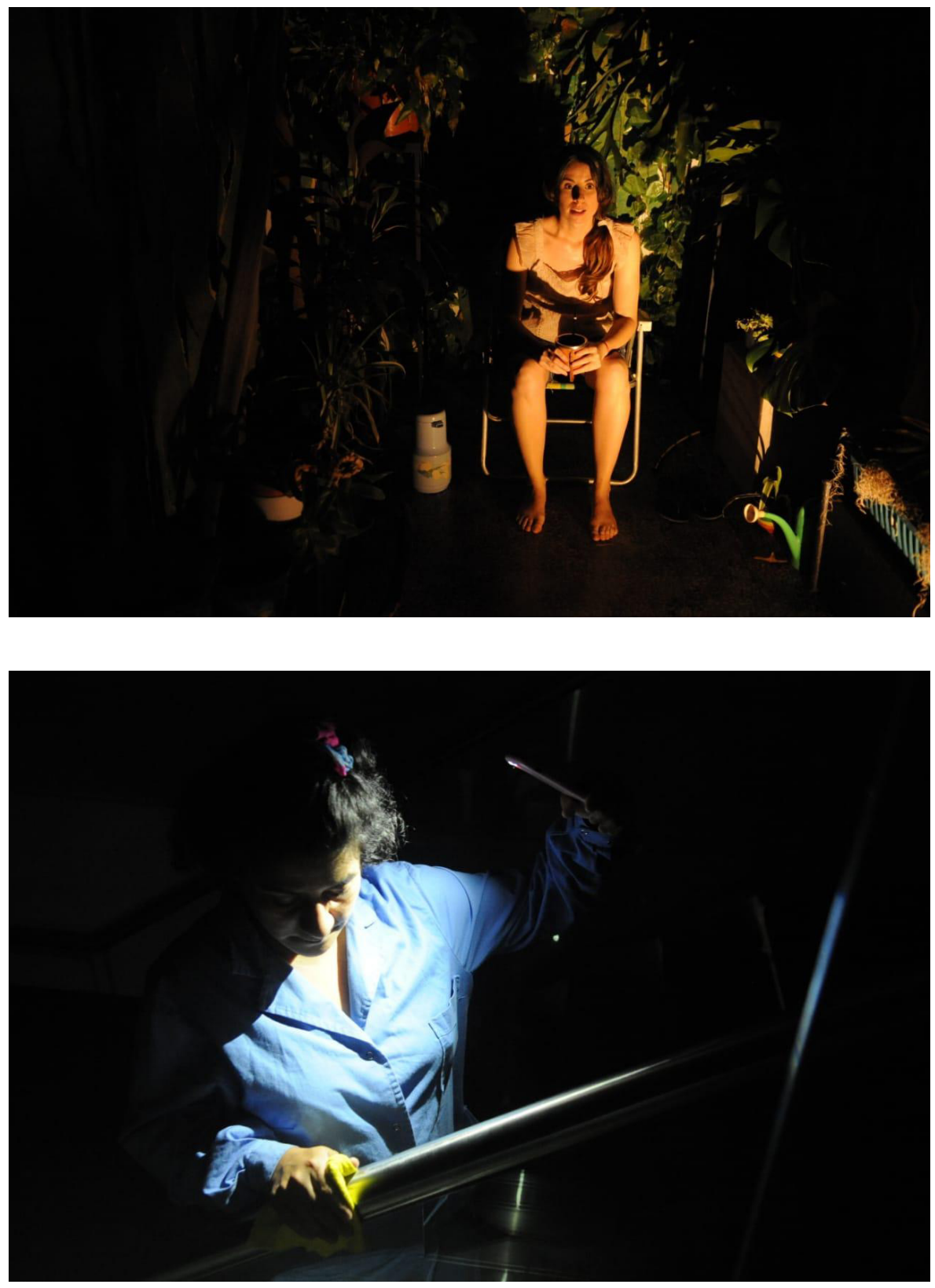

El lugar otorgado al espectador en la puesta merece una mención aparte, puesto que la incertidumbre que genera zambullirse a solas con una actriz en un espacio no convencional como lo es un gabinete, comienza a percibirse tiempo antes de ingresar a la misma. La intimidad del espacio compartido, la cercanía de los cuerpos, permite una invitación distinta al mundo ficcional creado, la falta de presencia no es opción. Unx también es observadx, invitadx a realizar acciones, es parte de la propuesta, en ese sentido se convierte en un espectador emancipadx, tal como expresaron en diversas ponencias, citando a Jacques Ranciere, las propias Monomujer, para quienes la práctica y la teoría se muestran indisolubles. Específicamente en su trabajo, 
"Monomujer, teatro para un espectador. De la contemplación a la creación: el espectador emancipado", presentado en el marco del Congreso de Tendencias Escénicas de la Universidad de Palermo, en febrero de 2020, las actrices señalan al respecto:

Todo nuestro enfoque creativo está centrado en la experiencia del espectador estando solo, siendo el único, identificándose por lo percibido en el proceso de comunicación teatral (...)el espectador es invitado a tomar decisiones, a cumplir un nuevo rol, ya que la emergencia de ser ese único público lo lleva a que se produzca el acontecimiento donde abandona su calidad de espectador para ser ahora intérprete, autopoiético, creador.

Por último, se observa un elemento más que remite a la centralidad del espectador: al salir del teatro, el público se encuentra con un cuadernito para dejar las impresiones, comentarios, emociones, vinculadas al acontecimiento vivido. Tal es la movilización que se siente luego de la experiencia que no alcanzan las palabras para expresar lo vivido. Por lo tanto, el agradecimiento no puede ser de otra forma que interminable.

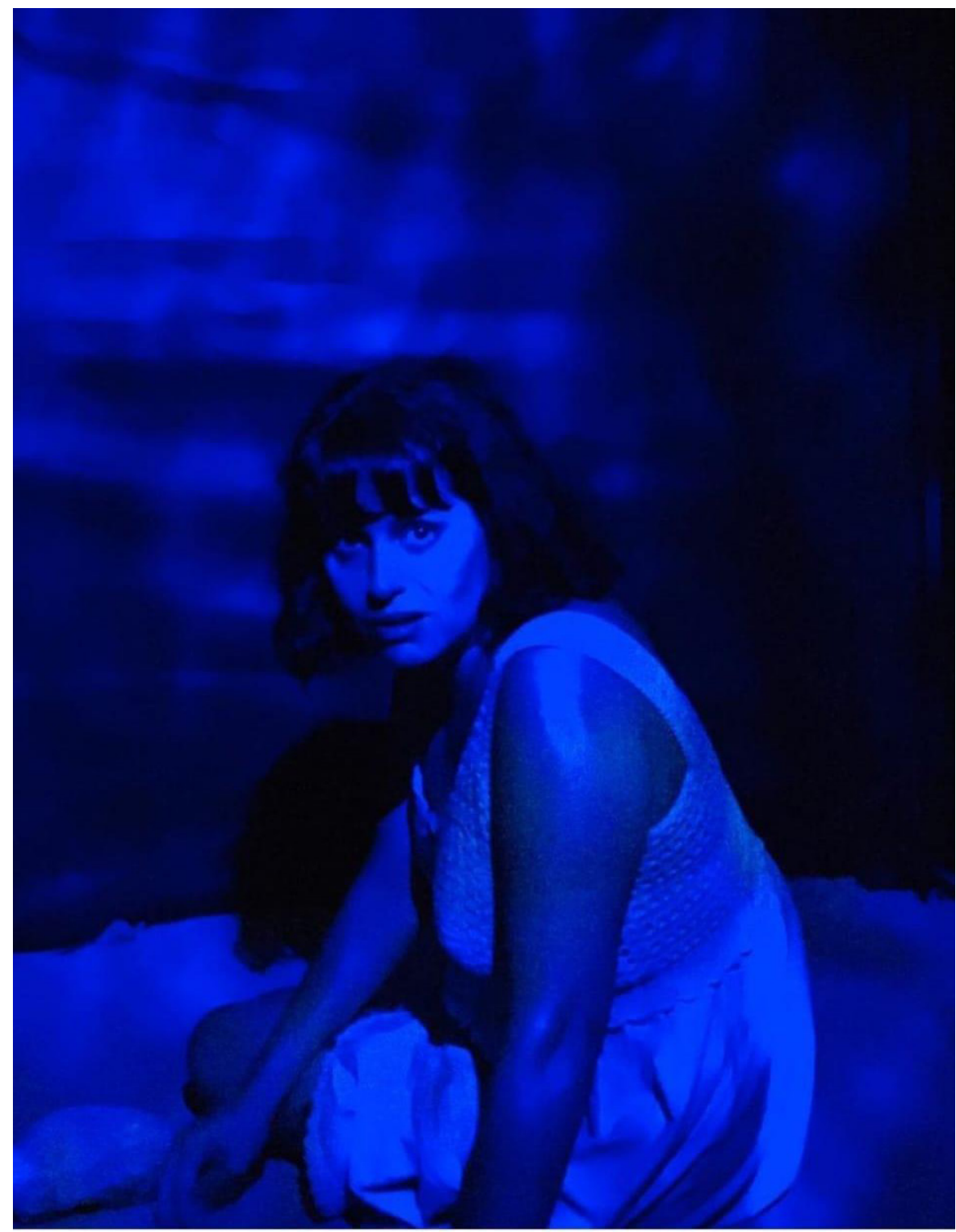




\section{Q Bibliografía}

" Curet V, Conde J, Mendoza O, Moreira L, Sanchez, J, Vilas M, Bonessa E, García M. (2020). "Monomujer, teatro para un espectador. De la contemplación a la creación: el espectador enmancipado", Congreso de Tendencias Escénicas de la Universidad de Palermo, febrero. 